\title{
Nonlinear PI Control with Adaptive Interaction Algorithm for Multivariable Wastewater Treatment Process
}

\author{
S. I. Samsudin, ${ }^{1}$ M. F. Rahmat, ${ }^{2}$ and Norhaliza Abdul Wahab ${ }^{2}$ \\ ${ }^{1}$ Department of Industrial Electronics, Faculty of Electronics and Computer Engineering, Universiti Teknikal Malaysia Melaka, \\ Hang Tuah Jaya, 76100 Durian Tunggal, Melaka, Malaysia \\ ${ }^{2}$ Department of Control and Mechatronics Engineering, Faculty of Electrical Engineering, Universiti Teknologi Malaysia, \\ 81310 Skudai, Malaysia
}

Correspondence should be addressed to M. F. Rahmat; fuaad@fke.utm.my

Received 4 June 2014; Revised 1 September 2014; Accepted 2 September 2014; Published 25 September 2014

Academic Editor: Xuejun Xie

Copyright (C) 2014 S. I. Samsudin et al. This is an open access article distributed under the Creative Commons Attribution License, which permits unrestricted use, distribution, and reproduction in any medium, provided the original work is properly cited.

\begin{abstract}
The wastewater treatment plant (WWTP) is highly known with the nonlinearity of the control parameters, thus it is difficult to be controlled. In this paper, the enhancement of nonlinear PI controller (ENon-PI) to compensate the nonlinearity of the activated sludge WWTP is proposed. The ENon-PI controller is designed by cascading a sector-bounded nonlinear gain to linear PI controller. The rate variation of the nonlinear gain $k_{n}$ is automatically updated based on adaptive interaction algorithm. Initiative to simplify the ENon-PI control structure by adapting $k_{n}$ has been proved by significant improvement under various dynamic influents. More than $30 \%$ of integral square error and $14 \%$ of integral absolute error are reduced compared to benchmark PI for DO control and nitrate in nitrogen removal control. Better average effluent qualities, less number of effluent violations, and lower aeration energy consumption resulted.
\end{abstract}

\section{Introduction}

The wastewater treatment plant (WWTP) is naturally aimed to remove the suspended substances, organic material, and phosphate from the water before releasing it to the recipient. The best technology available was used to control the discharge of pollutants emphasized in biological process, namely, as activated sludge process (ASP). In ASP, the organic materials are oxidized by microorganisms. The organic material is then transformed into carbon dioxide and some incorporate into new cell mass. The new cell mass then forms sludge that contains both living and dead microorganisms and, thus, contains organic material, phosphorous, and nitrogen [1]. Referring to [2], the common problems in WWTP are caused by maintenance issues and poor effluent quality which are due to poor control approaches.

According to [3], aeration process is a crucial part of the whole ASP. It is a nontrivial task to transport the oxygen from the air bubbles to the cells of the microorganisms, thus the process is commonly described by the oxygen mass transfer coefficient $\left(K_{\mathrm{La}}\right)$. The $K_{\mathrm{La}}$ is, in general, nonlinear and depends on the aeration actuating system and the sludge conditions [4]. Indeed, as referred to in [5], the dissolved oxygen (DO) is stated as a key variable and commonly applied in controlling the ASP. The level of DO in the aerobic reactors has a direct influence on the microorganisms' activities in the activated sludge. The DO level should be sufficiently high so that enough oxygen can be delivered to the microorganisms in the sludge. However, an excessively high DO will require higher airflow rate and thus leads to higher energy consumption and deteriorate the sludge quality. Meanwhile, nitrogen removal in activated sludge requires two-step procedure which takes place simultaneously nitrification and denitrification processes. Nitrification is a process in which ammonium is oxidized to nitrate under aerobic (present oxygen) conditions. The nitrate formed by nitrification process, in turn, is converted into gaseous nitrogen under anoxic (absent oxygen) conditions, that is called denitrification. The improvement of $\mathrm{DO}$ concentration in aerated tanks and the nitrogen removal process contribute to big interest of activated sludge control. 
The proportional-integral (PI) technique is one of the control strategies that are frequently applied in WWTP. As referred to in [6], each part of PI controller highly contributes in achieving the control target. The proportional part is potential to increase the response speed and control accuracy while the integration part is normally used in eliminating the steady-state error of the system. The performances of several control strategies with PI controller to the WWTP have been discussed in $[7,8]$. However, it is hard to achieve high control performance in all operating conditions with a linear PI controller due to different dynamic behaviours of the WWTP control parameters. More retuning task will always be demanded for a fixed-gain PI controller. Therefore, a controller that is potential to maintain a balance of DOs concentrations and nitrogen removal process during the set-point changes is highly demanded. Many approaches have been developed in improving the adaptability and robustness of the controller such as self-tuning method, general predictive control, fuzzy logic, and neural network strategy. However, predictive control technique may require more complex control structure while human knowledge and system's experts are strongly demanded in adaptive fuzzy controller. Besides, the crucial work is concentrated in estimating all of the input-output data within such a complex system and in determining the appropriate structure of the neural network controller.

Under these circumstances, enhanced nonlinear PI (ENon-PI) controller is proposed to compensate the nonlinearity of the control parameters hence to improve the performance of the conventional linear PI controller. The design of the ENon-PI controller is basically referred to [9] where the linear fixed-gain PI controller is cascaded to a bounded nonlinear gain. As referred to in [9], the nonlinear gain function has two parameters to be determined in initial simulation such as the range of variation, $e_{\max }$, and the rate of variation, $k_{n}$. Difficulties come to identify the appropriate combination of these parameters especially for a complex nonlinear system. Therefore, modifications to the ENon-PI to automate one of the parameters are obviously proposed. The idea is to automatically update $k_{n}$ using simple updating algorithm, namely, as adaptive interaction algorithm (AIA). The theoretical of adaptive interaction is previously applied in neural network and PID control as referred to in $[10,11]$, respectively. AIA is generally a technique in which a system is decomposed into subsystems where an adaptation exists between them. It is believed that the $k_{n}$ is potential to be updated with respect to proportional control part as referred to in [11].

Two case studies are proposed for control design strategies with respect to dynamic behaviors of the WWTP. Case 1 highlights the improvement of the ASP with respect to DO concentration in all aerated tanks called $\mathrm{DO}_{345}$ control while the improvement of nitrogen removal process is aimed in Case 2. Cases 1 and 2 are considered due to different average time constant for DO and nitrate which is in minutes and several hours, respectively. In particular, the WWTP is naturally a multivariable system that is basically described as a system with more than one control loop. Changes in any input will generally affect all the outputs due to interaction between
TABLE 1: List of the acronyms.

\begin{tabular}{ll}
\hline Acronyms & Descriptions \\
\hline AE & Aeration energy \\
AIA & Adaptive interaction algorithm \\
ASM1 & Activated Sludge Model 1 \\
ASP & Activated sludge process \\
BSM1 & Benchmark Simulation Model No. 1 \\
DO & Dissolved oxygen \\
$\mathrm{DO}_{q}$ & Dissolved oxygen control of tank $q, q=3,4,5$ \\
$\mathrm{DO}_{345}$ & Dissolved oxygen control of tanks 3, 4, and 5 \\
$e$ & Error \\
$e_{q}$ & Error of tank DO $q, q=3,4,5$ \\
$\mathrm{ENon}-\mathrm{PI}$ & Enhanced nonlinear PI \\
$\mathrm{IAE}$ & Integral of absolute error \\
$\mathrm{ISE}$ & Integral of square error \\
$k_{\text {non }}$ & Nonlinear gain \\
$k_{n}$ & Rate variation of nonlinear gain \\
$K_{\mathrm{Laq}}$ & Air flow rate of tank $q, q=3,4,5$ \\
$K_{p}$ & Proportional gain \\
$K_{i}$ & Integral gain \\
$\mathrm{Mean}(|e|)$ & Absolute error \\
$\mathrm{Max}(e)$ & Maximum absolute deviation from set-point \\
$Q_{\text {intr }}$ & Internal recycle flow rate \\
Std $(e)$ & Standard deviation of the error \\
$\mathrm{WWTP}$ & Wastewater treatment plant \\
\hline &
\end{tabular}

the inputs and outputs variables. However, a decentralized controller is a simple approach of multivariable controller designs. As a result, the plant to be controlled is essentially a collection of independent subplants where each element in the plant may be designed independently. The proposed Enon-PI is developed in decentralized control structure in both simulation cases. To further extend, the study on how the ENon-PI controller performs under various different dynamic conditions is covered. The proposed ENon-PI controller is then tested to an updated Benchmark Simulation Model No. 1 (BSM1) with more complex sensors and noises as updated in [12].

The paper is organized as follows. The BSM1 is explained in Section 2 while the development of ENon-PI with adaptation algorithm is presented in Section 3. The simulation result and discussion of well-tuned ENon-PI controller are presented in Section 4. Finally, Section 5 concludes the paper. For convenience of discussion, Table 1 lists the acronyms that frequently used in the paper.

\section{Benchmark Simulation Model No. 1 (BSM1)}

The WWTP used in the simulation is the benchmark plant developed in [12]; referred as BSM1. The plant consists of five tanks where the first two compartments are anoxic zones followed by three aerobic tanks as shown in Figure 1. Each tank is assumed to have constant volume of $1000 \mathrm{~m}^{3}, 1000 \mathrm{~m}^{3}, 1333 \mathrm{~m}^{3}, 1333 \mathrm{~m}^{3}$, and $1333 \mathrm{~m}^{3}$, respectively. 


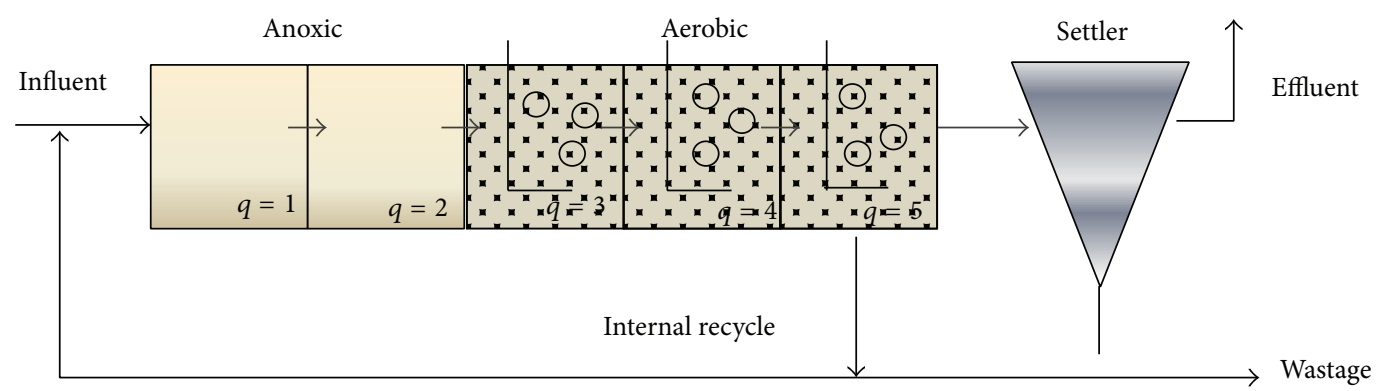

FIgure 1: The plant layout of the BSM1.

The effluent from the last tank is connected in series to a settler of constant volume of $6000 \mathrm{~m}^{3}$. The BSM1 is widely used as a standard model based on the most popular IWA Activated Sludge Model No. 1 (ASM1) proposed in [13]. The ASM1 was developed as to describe the removal of ammonium nitrogen and organic carbon. Meanwhile, the model proposed by [14] by was chosen to resemble the behavior of the secondary settler. The BSM1 is default controlled by PI controller where two control loops of nitrate in the second anoxic tank and the DO concentration in the final tank are emphasized. The performances of the benchmark PI are always used as comparison to the proposed controller. Detail on the model can be referred in [12].

2.1. Influent Load. To investigate the performance of the control strategy in various weather situations, three dynamic input files including dry, rain, and storm events that have realistic variations in the effluent flow rate and composition have been used. The data used for the estimation and control are sampled with a sampling period of 15 minutes given as

$$
\left[\begin{array}{lllllllllllllll}
\text { time } & S_{I} & S S & X_{I} & X_{S} & X_{\mathrm{BH}} & X_{\mathrm{BA}} & X_{P} & S_{\mathrm{O}} & S_{\mathrm{NO}} & S_{\mathrm{NH}} & S_{\mathrm{ND}} & X_{\mathrm{ND}} & S_{\mathrm{ALK}} & Q_{o}
\end{array}\right]
$$

In any influent: $S_{\mathrm{O}}=0 \mathrm{~g}(-\mathrm{COD}) \mathrm{m}^{3} ; X_{\mathrm{BA}}=0 \mathrm{~g} \mathrm{COD} \mathrm{m}^{-3}$; $S_{\mathrm{NO}}=0 \mathrm{~g} \mathrm{~N} \mathrm{~m}^{-3} ; X_{P}=0 \mathrm{~g} \mathrm{COD} \mathrm{m}^{-3} ; S_{\mathrm{ALK}}=7 \mathrm{~mol} \mathrm{~m}^{-3}$. The description of influent' variables is presented in Table 2.

The dry influent contains two weeks of dynamic dry weather influent data. The rain influent is based on the dry weather file with an added rain event during the second week. Similarly, the storm influent file is also based on the dry weather file but added with two storm events during the second week. There is a constant influent with constant flow and composition that is used during the system simulation under steady state condition. Refer to [12] for detailed explanation.

2.2. Performance Assessment. Two-level performance assessment is highlighted in controlling the WWTP. The local control loop is assessed on the means of absolute error $($ Mean $(|e|))$, the integral of absolute error (IAE), the integral of square error (ISE), the maximum absolute deviation from set-point $(\operatorname{Max}(e))$, and the standard deviation of the error $(\operatorname{Std}(e))$ at the first level. Meanwhile, the second level investigates the effect of the control strategy on the plant process operation with respect to economical and quality part. Two measuring assessments are considered in the simulation such as the effluent violations and the aeration energy consumed.

2.2.1. The Effluent Violations. Table 3 indicates the constraints of the effluent water quality. The flow-weighted average effluent concentrations of the following variables must meet their corresponding limitations. Besides, the effluent violations can be reported through the number of violations and the percentage time plant is in violation. This quantity indicates the frequency of the plant effluent increases above the effluent constraint.

2.2.2. The Aeration Energy. The index of aeration energy (AE) is described as in (2). $K_{\mathrm{Laq}}(t)$ is the oxygen transfer coefficient in each tank, $q$. The $\mathrm{AE}$ is calculated for the last 7 days, $T$ of the dynamic test weather conditions with unit of $\mathrm{kWhday}^{-1}$. Consider

$$
\mathrm{AE}=\frac{S_{o}^{\text {sat }}}{T \cdot 1.8 \cdot 1000} \int_{7 \text { days }}^{14 \text { days }} \sum_{k=1}^{5} V_{q} \cdot K_{\mathrm{Laq}}(t) d t .
$$

\section{Development of Enhanced Nonlinear PI Controller}

3.1. The Case Study. As mentioned, two case studies are highlighted for control design strategies. The improvement of the ASP with respect to DO concentration in all aerated tanks, tank $3\left(\mathrm{DO}_{3}\right)$, tank $4\left(\mathrm{DO}_{4}\right)$, and tank $5,\left(\mathrm{DO}_{5}\right)$ called $\mathrm{DO}_{345}$ control is aimed in Case 1. Meanwhile, the improvement of the nitrogen removal process of nitrate and $\mathrm{DO}_{5}$ control is next highlighted in Case 2.

3.1.1. Case 1: Controlling the Aerated Tanks $\left(D_{345}\right)$. For decentralized control structure, the WWTP is partitioned 


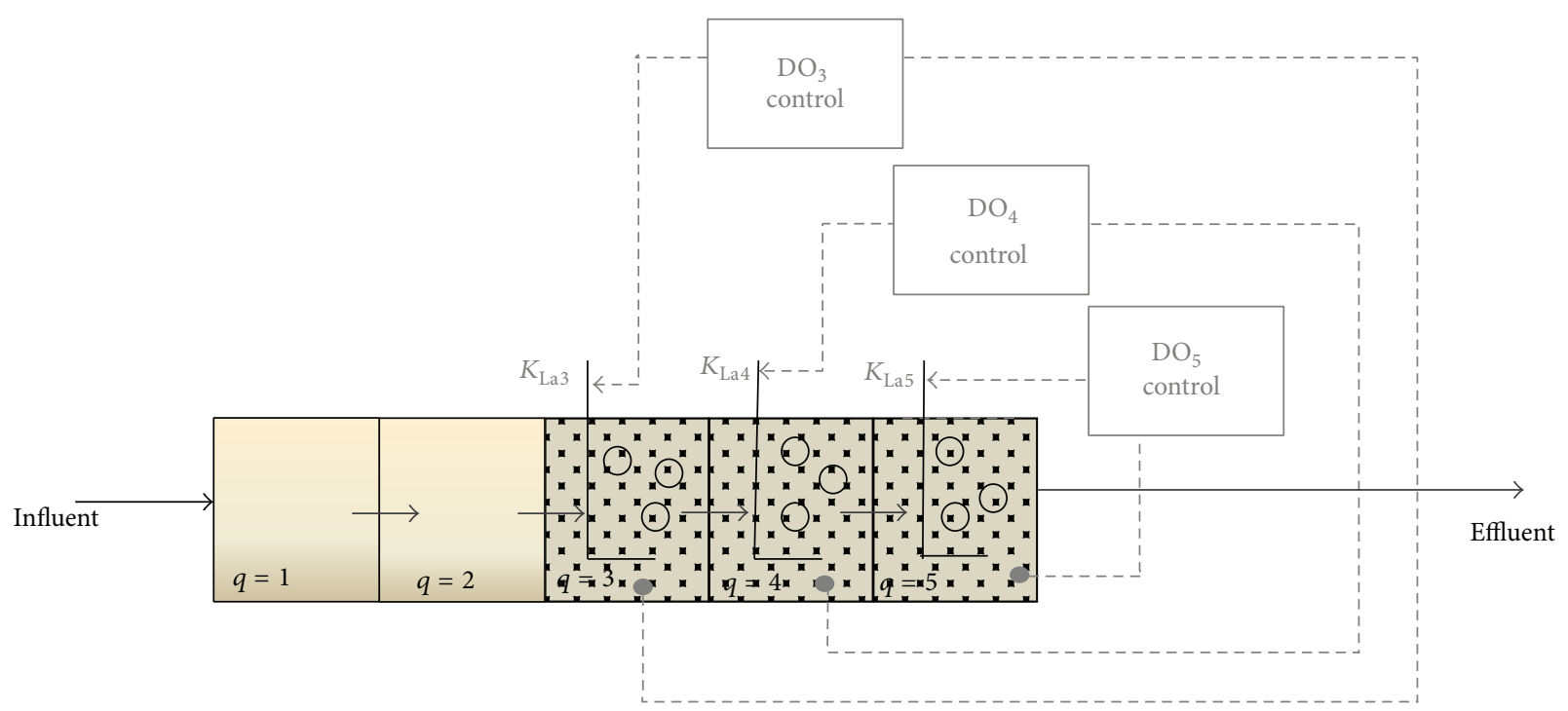

FIgURE 2: ENon-PI control for the last three aerated tanks in Case 1.

TABLE 2: Influent data.

\begin{tabular}{ll}
\hline Variables & Descriptions \\
\hline$S_{I}$ & Soluble inert organic matter \\
$S_{S}$ & Suspended solids \\
$S_{\mathrm{O}}$ & Dissolve oxygen \\
$S_{\mathrm{NO}}$ & Nitrate \\
$S_{\mathrm{NH}}$ & Ammonium and ammonia nitrogen \\
$S_{\mathrm{ND}}$ & Soluble biodegradable organic nitrogen \\
$S_{\mathrm{ALK}}$ & Alkalinity \\
$X_{I}$ & Particulate inert organic matter \\
$X_{S}$ & Slowly biodegradable substrate \\
$X_{\mathrm{BH}}$ & Active heterotrophic biomass \\
$X_{\mathrm{BA}}$ & Active autotrophic biomass \\
$X_{P}$ & Particulate products arising from biomass decay \\
$X_{\mathrm{ND}}$ & Particulate biodegradable organic nitrogen \\
$Q_{o}$ & Input flow rate \\
\hline
\end{tabular}

TABLE 3: Constraints of the effluent water quality.

\begin{tabular}{lc}
\hline Variables & Value \\
\hline Total nitrogen $\left(\mathrm{N}_{\text {tot }}\right)$ & $18 \mathrm{~g} \mathrm{~N} \mathrm{~m}^{-3}$ \\
Chemical oxygen demand $\left(\mathrm{COD}_{5}\right)$ & $100 \mathrm{~g} \mathrm{COD} \mathrm{m}^{-3}$ \\
Ammonia $\left(S_{\mathrm{NH}}\right)$ & $4 \mathrm{~g} \mathrm{~N} \mathrm{~m}^{-3}$ \\
Total suspended solids $(\mathrm{TSS})$ & $30 \mathrm{~g} \mathrm{SS} \mathrm{m}^{-3}$ \\
Biochemical oxygen demand $\left(\mathrm{BOD}_{5}\right)$ & $10 \mathrm{~g} \mathrm{BOD} \mathrm{m}^{-3}$ \\
\hline
\end{tabular}

into three SISO subsystems contributing to three ENon-PI controllers. The implementation of $\mathrm{DO}_{345}$ control is shown in Figure 2.

3.1.2. Case 2: Controlling the Nitrate- $\mathrm{DO}_{5}$. For the nitrogen removal process, the ENon-PI controller is set to work correspondingly to the benchmark PI. The implementation of the controller is shown in Figure 3.
3.2. The Controller. For a conventional linear PI controller, the error signal is used to generate the proportional $(P)$ and integral $(I)$ control actions and to be summed in producing the control signal as generally expressed as in

$$
u(t)=K_{p} e(t)+K_{i} \int_{0}^{t} e(t) d t
$$

where $K_{p}$ and $K_{i}$ are the proportional and integral coefficients of the PI controller, respectively. However, the fixed-gains of conventional linear PI controller have the limitation in controlling the time-variant characteristics and the process nonlinearities of the WWTP [15]. This problem can be alleviated by employing nonlinear elements in the PI control scheme and thus leads the development of the ENon-PI controller.

As discussed, the ENon-PI is designed by cascading a sector-bounded nonlinear gain to linear PI controller as described in (4). The nonlinear gain, $k_{\text {non }}$ is a function of error with respect to the changes of $k_{n}$, that acts on the error in producing the scaled error; $f(e)=k_{\text {non }}\left(e, k_{n}\right) \cdot e(t)$. The $f(e)$ is then input to the PI controller thus generating the control action as

$$
\begin{aligned}
u_{\mathrm{ENon}-\mathrm{PI}}(t) & =\left[k_{p} e(t)+k_{i} \int_{0}^{t} e(t) d t\right] \cdot f(e) \\
& =\left[k_{p} e(t)+k_{i} \int_{0}^{t} e(t) d t\right]\left[k_{\mathrm{non}}\left(e, k_{n}\right) \cdot e(t)\right] .
\end{aligned}
$$

The $k_{\text {non }}$ can be expressed by any nonlinear general function such as sigmoidal function, the hyperbolic function, and the piecewise linear function as explained in [16]. However, the $k_{\text {non }}$ used in the simulation are described in (5) and (6). 


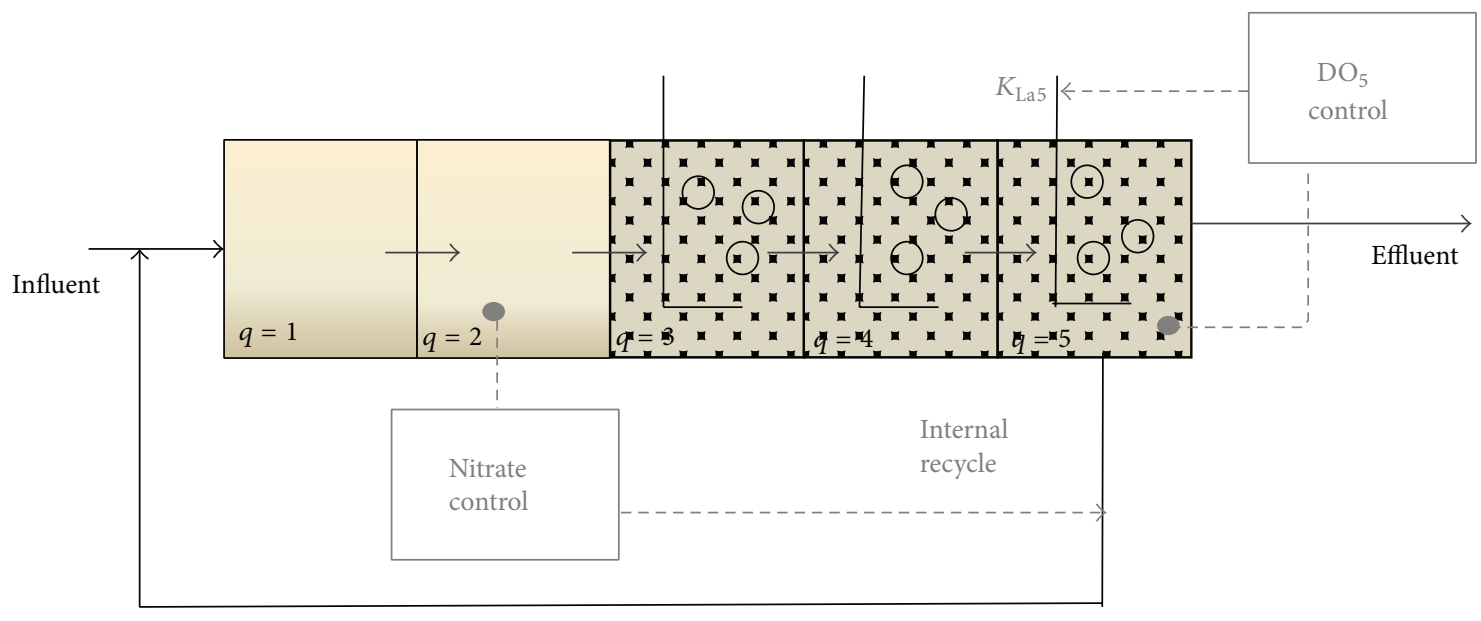

Figure 3: ENon-PI control for the nitrate- $\mathrm{DO}_{5}$ in Case 2.

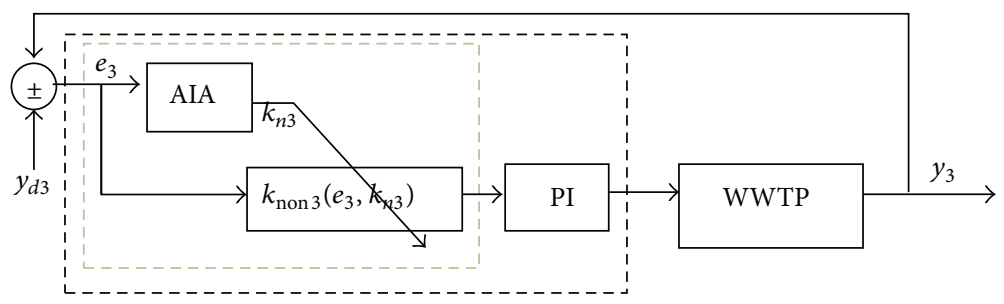

FIgURE 4: The block diagram of ENon-PI controller for $\mathrm{DO}_{3}$ control.

Notice that the $k_{n}$ is automatically updated by the AIA while $e_{\max }$ is the user-defined positive constant. Consider

$$
k_{\text {non }}\left(e, k_{n}\right)=\left[\frac{\exp ^{\left(k_{n} e\right)}+\exp ^{\left(k_{n} e\right)}}{2}\right] \text {, }
$$

where

$$
e= \begin{cases}e & |e| \leq e_{\max } \\ \operatorname{sign}(e) \cdot \sqrt{\left|e_{\max }\right|} & |e|>e_{\max } .\end{cases}
$$

3.3. The Algorithm. The work on enhanced nonlinear PID by [9] is extended to adaptively update the $k_{n}$. It is believed that the characteristic of $k_{n}$ is potential to be manipulated based on AIA. As mentioned, the AIA is generally a technique in which a system is decomposed into subsystems where an adaptation exists between them. The $k_{n}$ is updated with respect to proportional control part as referred to in [11]. The typical decomposition of a system for an adaptive interaction and the detail on AIA can be further referred in $[10,11,17]$.

In conjunction to Case $1, \mathrm{DO}_{3}, \mathrm{DO}_{4}$, and $\mathrm{DO}_{5}$ control loops are involved. However, the $\mathrm{DO}_{3}$ concentration is first considered to present the applied algorithm. The block diagram of ENon-PI of $\mathrm{DO}_{3}$ control loop is shown in Figure 4 . $y_{d 3}$ and $y_{3}$ are desired and measured outputs that result in the error of $\mathrm{DO}_{3}, e_{3}$. The $e_{3}$ is then applied by AIA in updating the $k_{n 3}$ for the variation of the $k_{\text {non3 }}$. The integration of the functional of $k_{\text {non3 }}$ to the PI controller develops the ENon-PI for $\mathrm{DO}_{3}$ control.

The aim here is to update $k_{n 3}$ of the nonlinear gain for the third tank using the the AIA so that the performance index which is the $e_{3}$ as in (7) is minimized. With respect to AIA, it is believed that interaction/adaptation of $k_{n 3}$ exists between the proportional gain transfer function of $e_{3}, A_{3}$, and the functional of the $k_{\text {non3 }}$. The gradient method as given in (8) is then applied. Consider

$$
\begin{aligned}
& E_{3}=e_{3}{ }^{2}=\left(y_{3}-y_{d 3}\right)^{2}, \\
& \dot{k}_{n 3}=-\gamma_{3} \frac{d E_{3}}{d y_{3}} \circ \dot{F}\left[x_{3}\right] \circ A_{3}
\end{aligned}
$$

$\Upsilon_{3}$ is the adaptation gain while $\dot{F}$ is the Frechet derivative in relation to the plant input, $x_{3}$, and the output, $y_{3}$. The adaptation of $k_{n 3}$ is then reduced to

$$
\begin{aligned}
\dot{k}_{n 3} & =2 \gamma_{3}\left(y_{3}-y_{d 3}\right) \dot{F}\left[x_{3}\right] \circ A_{3} \\
& =2 \gamma_{3} e_{3} \dot{F}\left[x_{3}\right] \circ A_{3} .
\end{aligned}
$$

The functional $F\left[x_{3}\right]$ can be written in the convolution form as in (10). $g_{3}(t)$ is the impulse response of the linear time invariant system for $\mathrm{DO}_{3}$ while $*$ denotes convolution. 
Therefore, the Frechet derivative can be expressed as in (11). Consider

$$
\begin{gathered}
F\left[x_{3}\right]=g_{3}(t) * x_{3}(t)=\int_{0}^{t} g_{3}(t-\tau) x_{3}(\tau) d \tau, \\
\dot{F}\left[x_{3}\right] \circ A_{3}=\int_{0}^{t} g_{3}(t-\tau) A_{3}(\tau) d \tau=g_{3}(t) * A_{3}(t) .
\end{gathered}
$$

However in many practical systems, the Frechet derivative can be approximated as in (12) where $A_{3}$ is an arbitrary function and $\sigma_{3}$ is a constant value. Consider

$$
\dot{F}\left[x_{3}\right] \circ A_{3}=\sigma_{3} A_{3} .
$$

This result approximates Frechet tuning algorithm as presented in

$$
\dot{k}_{n 3}=2 \gamma_{3} e_{3} \dot{F}\left[x_{3}\right] \circ A_{3}=2 \gamma_{3} e_{3} \sigma_{3} A_{3} .
$$

Let the adaptive coefficient, $\eta_{3}=2 \Upsilon_{3} \sigma_{3}$ and $\eta_{3}>0$ The tuning algorithm of $k_{n 3}$ thus can be simplified to (14). Therefore, $k_{n 3}$ might change and update it responses with time referring to the changes of $e_{3}$ in achieving good variation of the $k_{\text {non3 } 3}$. The general function of $k_{\text {non }}$ used in the simulation can be referred in (5). Consider

$$
\dot{k}_{n 3}=\eta_{3} e_{3} A_{3} .
$$

Taking $y_{d 4}$ and $y_{4}$ that represent the desired and measured outputs which result the error of $\mathrm{DO}_{4}, e_{4}$ besides $A_{4}$ that denotes the proportional gain of tank four, the procedures of (7)-(13) are repeated. This results in an approximate Frechet tuning algorithm for tank four as described in (15). The same goes to DO control of tank five thus contributing to $k_{n 5}$ as in (16). Notice that $\eta_{3}, \eta_{4}$, and $\eta_{5}$ are the adaptation coefficients of $k_{n 3}, k_{n 4}$, and $k_{n 5}$ in controlling the $\mathrm{DO}_{3}, \mathrm{DO}_{4}$, and $\mathrm{DO}_{5}$ concentrations, respectively. For simplicity, the proportional gains of $A_{3}, A_{4}$, and $A_{5}$ are always set to 1

$$
\begin{aligned}
& \dot{k}_{n 4}=\eta_{4} e_{4} A_{4}, \\
& \dot{k}_{n 5}=\eta_{5} e_{5} A_{5} .
\end{aligned}
$$

In fact, the procedures on (7)-(13) are repeated for nitrate control loop in Case 2. The tuning algorithm of $k_{n 2}$ is then described in (17). Meanwhile, similar algorithm presented in (16) is used for $\mathrm{DO}_{5}$ control. Consider

$$
\dot{k}_{n 2}=\eta_{2} e_{2} A_{2}
$$

\section{Results and Discussion}

The simulation procedures of BSM1 can be referred to in [12]. In the ideal case, the BSM1 is first simulated for 150 days to attain a quasi-steady-state using the constant influent input. This is done to guarantee that the initial conditions of the states are consistent. It then continued with 14-day simulation of dry influent to set up the plant for the dynamic benchmark simulation. Finally, the plant is simulated for the next 14 days with the dynamic test input weather with noises present. However, only the data of the last 7 days are evaluated in control assessment. For DO control, the sensor of class A with a measurement range of 0 to $10 \mathrm{~g}(-\mathrm{COD}) \mathrm{m}^{-3}$ and a measurement noise of $0.25 \mathrm{~g}(-\mathrm{COD}) \mathrm{m}$ is used. Meanwhile, a class $\mathrm{B} 0$ sensor with a measurement range of 0 to $20 \mathrm{gNm}^{-3}$ and measurement noise of $0.5 \mathrm{gNm}^{-3}$ is applied in nitrate control. Two case studies are considered in the simulation, $\mathrm{DO}_{345}$ control and nitrogen removal process control.

4.1. Case 1: Controlling the $\mathrm{DO}_{345}$. The $\mathrm{DO}$ concentrations in tank 3 , tank 4 , and tank 5 are set to $1.5 \mathrm{mg} \mathrm{L}^{-1}, 3 \mathrm{mg} \mathrm{L}^{-1}$, and $2 \mathrm{mg} \mathrm{L}^{-1}$, respectively, as referred to in [18]. Nevertheless, the previous work develops multivariable PID for COST simulation benchmark [19] instead of updated version [12] that is used in the present simulation. In addition, the oxygen mass transfer coefficient of $\mathrm{DO}_{3}\left(K_{\mathrm{La} 3}\right)$, the oxygen mass transfer coefficient of $\mathrm{DO}_{4}\left(K_{\mathrm{La} 4}\right)$, and the oxygen mass transfer coefficient of $\mathrm{DO}_{5}\left(K_{\mathrm{La} 5}\right)$ are constrained to a maximum of 360 day $^{-1}$. The $k_{n 3}, k_{n 4}$, and $k_{n 5}$ are automatically updated using AIA as described in (14)-(16). Meanwhile, the adaptive coefficients, $\eta_{3}, \eta_{4}$, and $\eta_{5}$ are set to 0.09. $e_{\max }=1$ is applied while the proportional gains and the integral time constants of linear PI controllers are set to 25 and 0.0020 , respectively.

4.2. Case 2: Controlling the Nitrate- $\mathrm{DO}_{5}$. The nitrate- $\mathrm{DO}_{5}$ control of the nitrogen removal process is considered in the second case. The $k_{n 2}$ and $k_{n 5}$ are automatically updated using AIA as referred to in (16)-(17). The internal recycle flow rate $\left(Q_{\text {intr }}\right)$ and the $K_{\mathrm{La} 5}$ are manipulated. To improve the nitrogen removal, the nitrate concentration is set to $1.0 \mathrm{gm}^{-3}$ with constrained $Q_{\text {intr }}$ up to 5 times of stabilized input flow rate, $92230 \mathrm{~m}^{3}$ day ${ }^{-1}$. The $\mathrm{DO}_{5}$ level is set to $2.0 \mathrm{gm}^{-3}$ with constrained $K_{\mathrm{La} 5}$ to a maximum of 360 day $^{-1}$. The $\eta_{2}$ and $\eta_{5}$ are similarly set to 0.09 while the $e_{\max }$ and the PI control gains as in Case 1 are maintained in the simulation.

4.3. Discussion. It is aimed to improve the performance for the set-point tracking of the load changes due to daily variations in different influents composition. As mentioned, the effectiveness of the proposed ENon-PI controller is investigated in two-level assessment, the performance of the controller and the performance of activated sludge process compared to benchmark PI.

4.3.1. The Performance of the Controller. The ENon-PI is first assessed by investigating the Mean $(|e|)$, the IAE, the ISE, the $\operatorname{Max}(e)$, and the $\operatorname{Std}(e)$. As for comparison, the performance of ENon-PI with adaptive $k_{n}$ is also compared to ENon-PI with fixed $k_{n}$. For this purpose, the $k_{n 3}, k_{n 4}$, and $k_{n 5}$ are set to 0.01 for $\mathrm{DO}_{345}$ control. Similarly $k_{n 5}$ is used for $\mathrm{DO}_{5}$ while $k_{n 2}$ is set to 0.1 for nitrate in nitrate- $\mathrm{DO}_{5}$ control. Referring to Table 4, obvious improvement is obtained in Case 1 by ENonPI controller compared to benchmark PI controller. However, as referred to in Table 5, significant improvement is observed for nitrate compared to $\mathrm{DO}_{5}$ in Case 2. Difficulties come to 
TABLE 4: Comparative of controller performance for Case 1.

\begin{tabular}{|c|c|c|c|c|c|c|}
\hline & & Benchmark PI & & & & \\
\hline & & & & $-\%$ & & $-\%$ \\
\hline & Mean $(|e|)$ & 0.0840 & 0.0695 & 17.3052 & 0.0688 & 18.1381 \\
\hline & IAE & 0.5883 & 0.4814 & 18.1724 & 0.4813 & 18.1894 \\
\hline Dry & ISE & 0.0840 & 0.0547 & 34.8616 & 0.0547 & 34.8616 \\
\hline & $\operatorname{Max}(\mathrm{dev})$ & 0.3963 & 0.3101 & 21.7532 & 0.3058 & 22.8382 \\
\hline & Std(dev) & 0.1095 & 0.0884 & 19.2915 & 0.0884 & 19.2915 \\
\hline & $\operatorname{Mean}(|e|)$ & 0.0795 & 0.0688 & 13.4939 & 0.0666 & 16.2601 \\
\hline & IAE & 0.5567 & 0.4665 & 16.2056 & 0.4665 & 16.2056 \\
\hline Rain & ISE & 0.0747 & 0.0513 & 31.3556 & 0.0512 & 31.4894 \\
\hline & $\operatorname{Max}(\mathrm{dev})$ & 0.3851 & 0.2992 & 22.2958 & 0.2868 & 25.5162 \\
\hline & Std(dev) & 0.1033 & 0.0856 & 17.1506 & 0.0855 & 17.2474 \\
\hline & Mean $(|e|)$ & 0.0809 & 0.0680 & 15.8978 & 0.0672 & 16.8872 \\
\hline & IAE & 0.5660 & 0.4702 & 16.9229 & 0.4701 & 16.9405 \\
\hline Storm & ISE & 0.0789 & 0.0523 & 33.6934 & 0.0522 & 33.8202 \\
\hline & $\operatorname{Max}(\mathrm{dev})$ & 0.3792 & 0.3005 & 20.7626 & 0.2970 & 21.6855 \\
\hline & Std(dev) & 0.1062 & 0.0864 & 18.6057 & 0.0864 & 18.6057 \\
\hline
\end{tabular}

TABLE 5: Comparative of controller performance for Case 2.

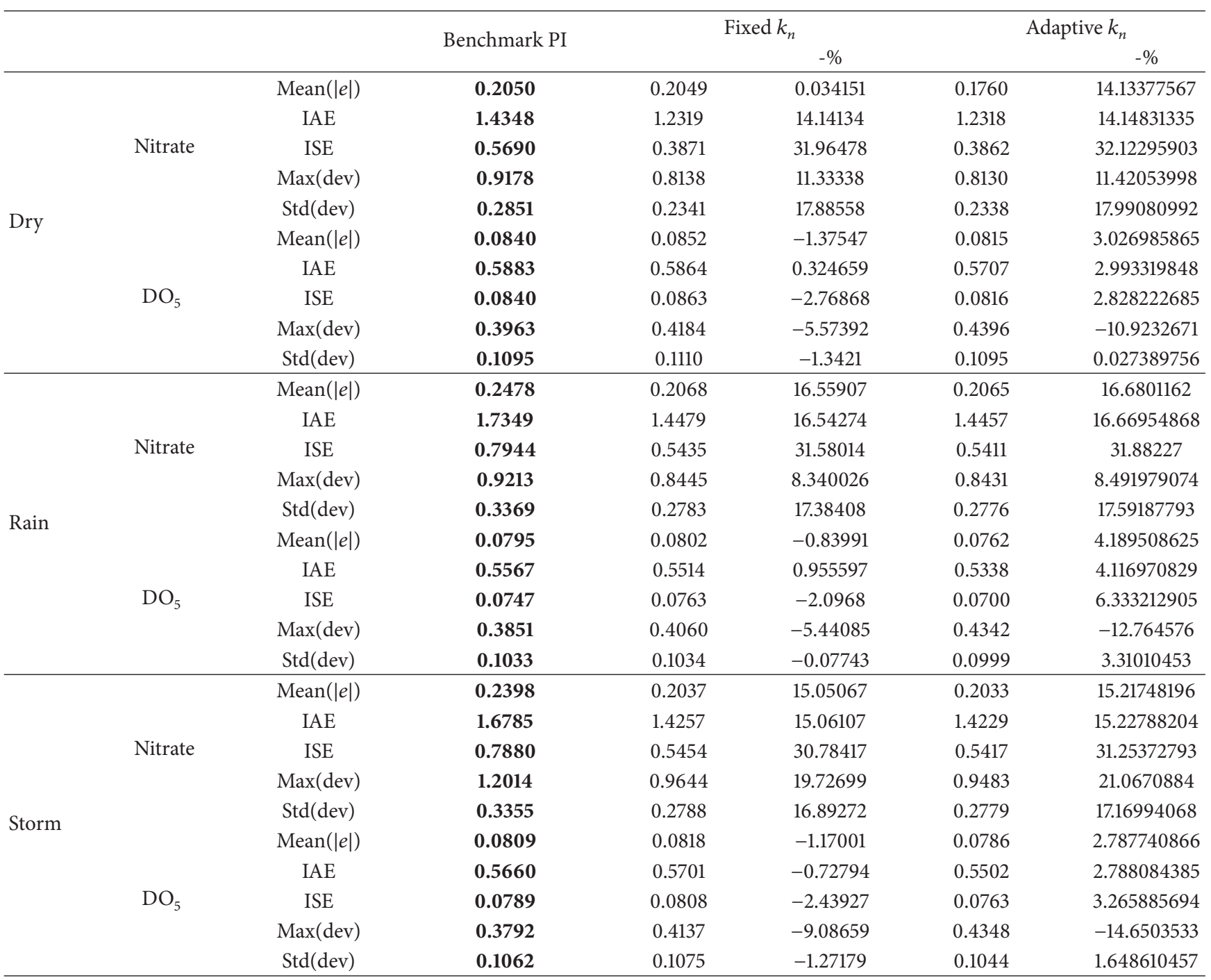



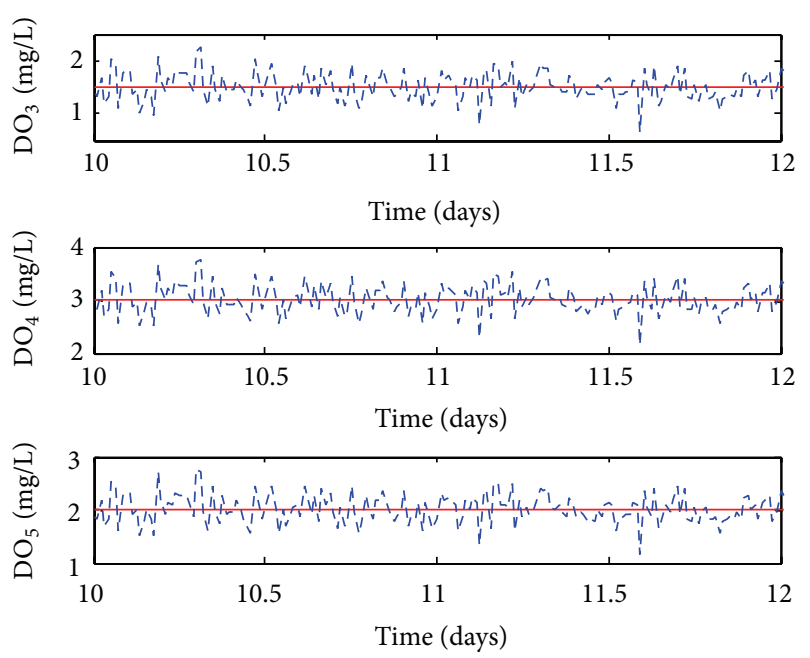

(a)
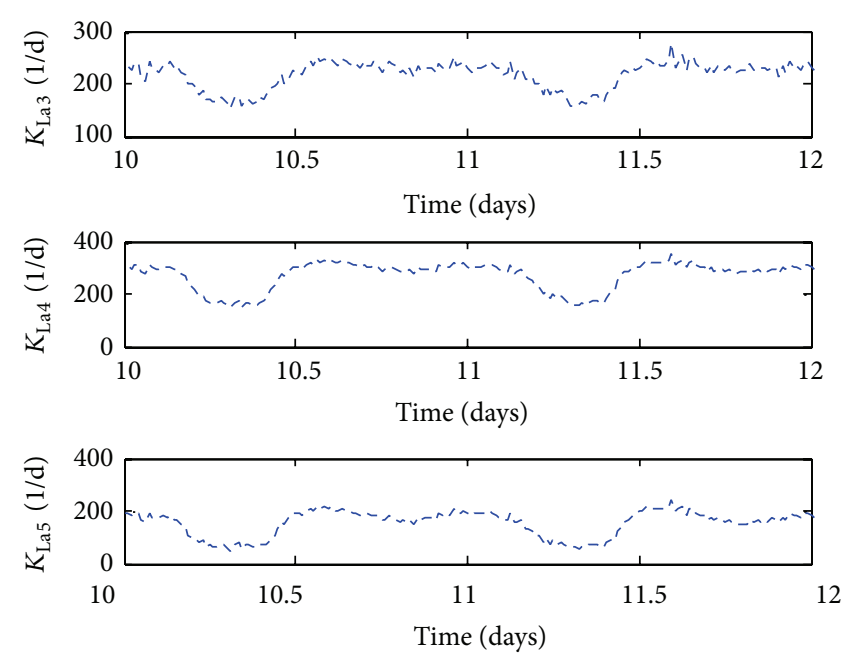

(b)

FIgURE 5: Variation of (a) output and (b) input variables under dry influent of Case 1.

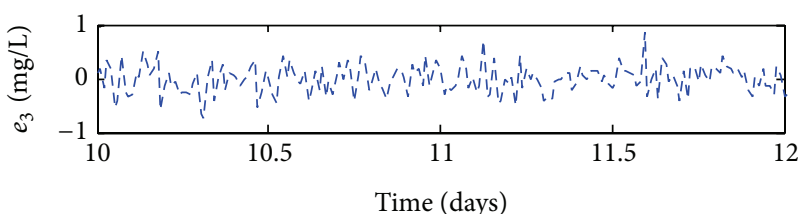

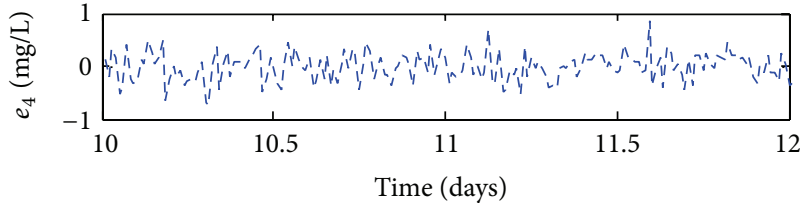

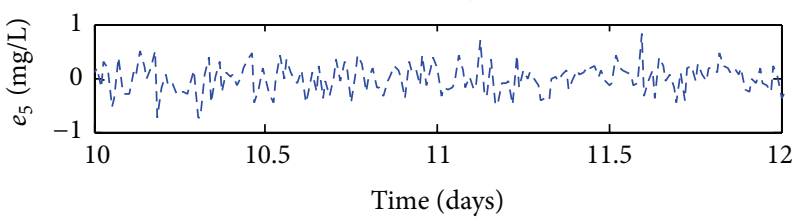

(a)
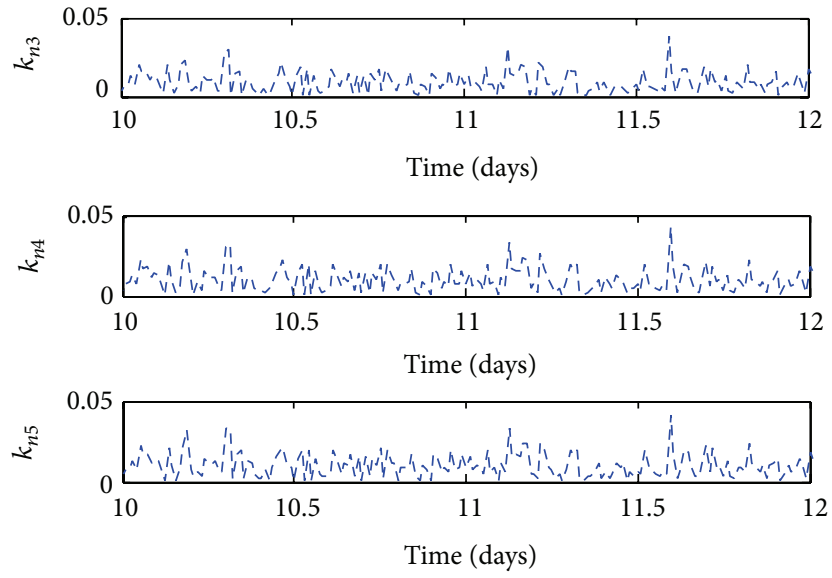

(b)

FIgURE 6: Variation of (a) error (b) rate variation under dry influent of Case 1.

control simultaneous nitrate and $\mathrm{DO}_{5}$ control loops in Case 2 that may due to different dynamic behaviours of the control parameters.

The variation of output and input variables of $\mathrm{DO}_{345}$ control in Case 1 under dry input weather by ENon-PI with adaptive $k_{n}$ is shown in Figure 5. It was seen that the ENon-PI controller with adaptive $k_{n 3}, k_{n 4}$, and $k_{n 5}$ manages well to keep $\mathrm{DO}_{3}, \mathrm{DO}_{4}$, and $\mathrm{DO}_{5}$ concentrations around the reference values. Besides, the input variables $K_{\mathrm{La} 3}, K_{\mathrm{La} 4}$, and $K_{\mathrm{La} 5}$ are always kept under the upper bounds. Meanwhile, Figure 6 shows the variation of the error and the adaptation of the $k_{n}$ resulted. As observed, higher $k_{n}$ is demanded for a higher error resulted.

The nitrate- $\mathrm{DO}_{5}$ control is then simulated with respect to benchmark PI, as applied in [12]. Figure 7 shows the comparative variation of output variables of nitrate and $\mathrm{DO}_{5}$ under rain input weather. Slight improvements are observed by ENon-PI with adaptive $k_{n 2}$ and $k_{n 5}$ for nitrate and $\mathrm{DO}_{5}$ concentrations compared to benchmark PI. Nevertheless, the improvements are obviously better than the fixed $k_{n}$. The variations of input variables of nitrate- $\mathrm{DO}_{5}$ control are next illustrated in Figure 8. Similarly, the $Q_{\text {intr }}$ and $K_{\mathrm{La} 5}$ are always kept under the upper bounds. Meanwhile, the variation of the errors and the adaptation of the rate variation resulted are illustrated in Figure 9.

4.3.2. The Performance of Activated Sludge Process. The second level of controller assessment is to investigate the effect of the ENon-PI control strategy on the process of an activated sludge. Firstly, the performances in average effluent concentrations are compared to benchmark PI and the fixed $k_{n}$, as indicated in Tables 6 and 7 for Cases 1and 2, 

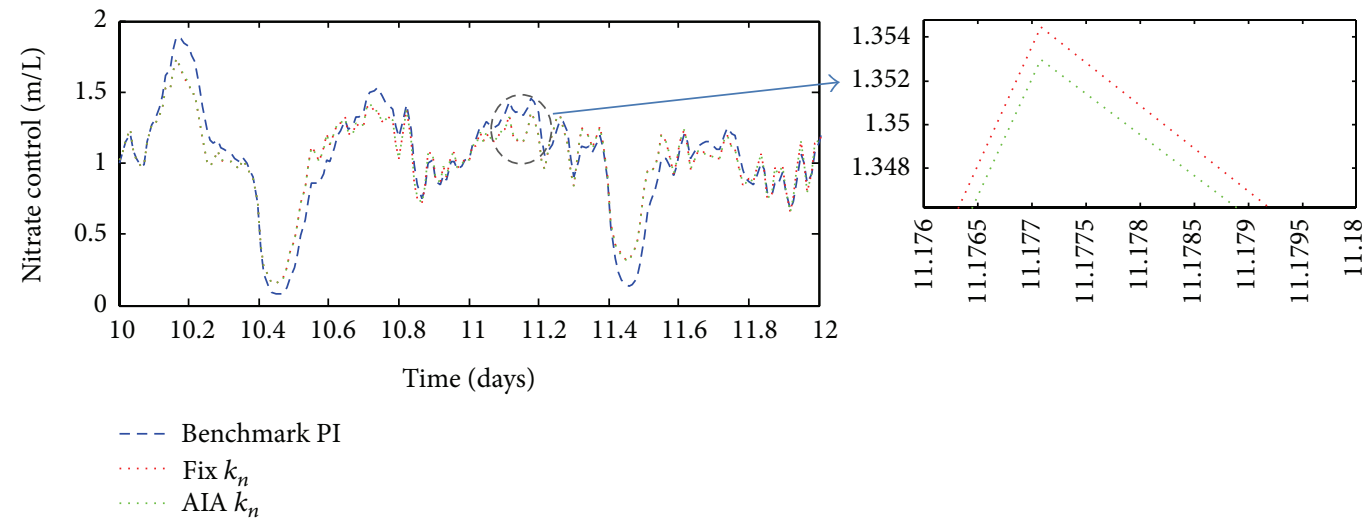

(a)
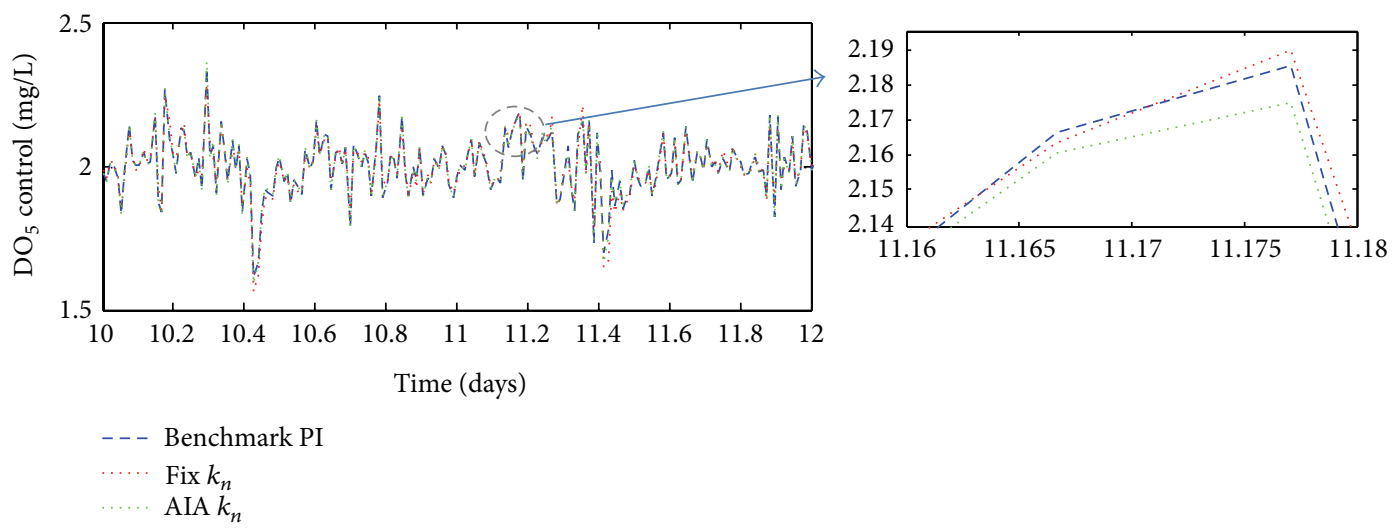

(b)

FIgURE 7: Variation of (a) nitrate (b) $\mathrm{DO}_{5}$ output variables under rain influent of Case 2.

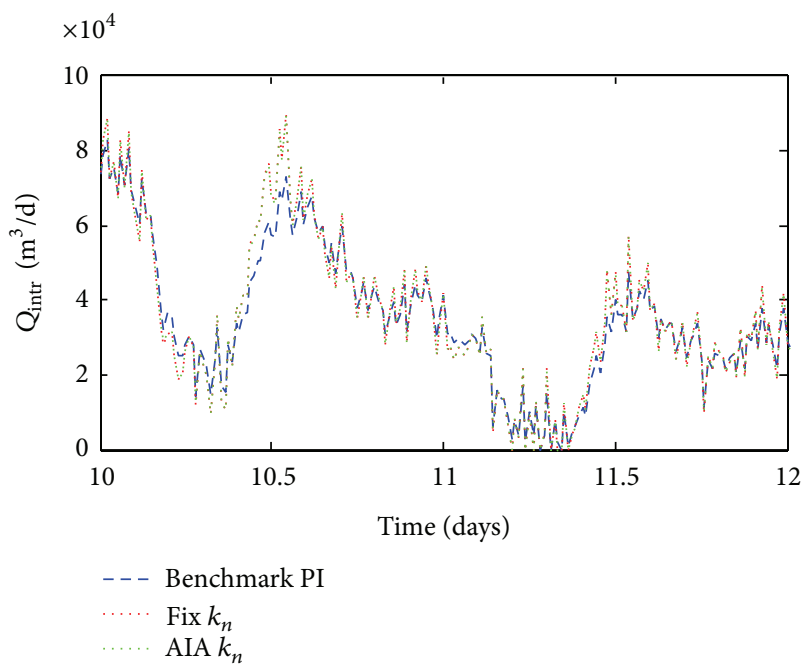

(a)

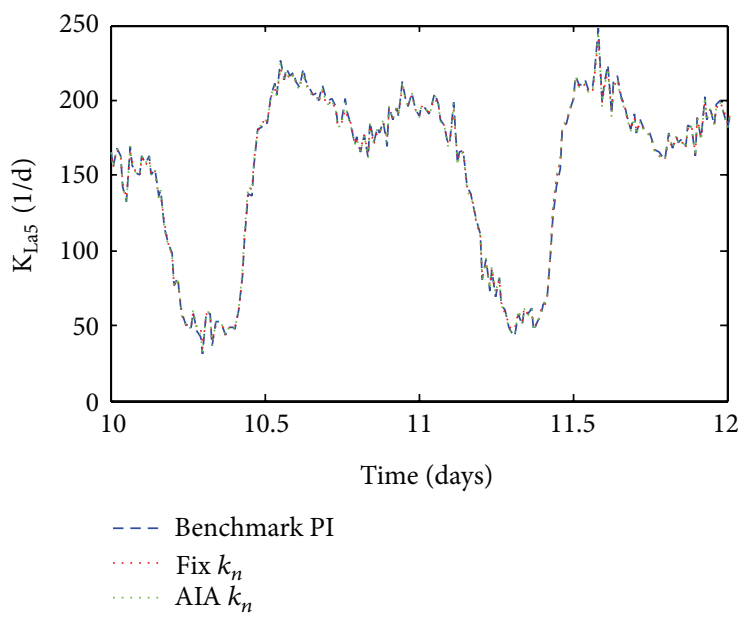

(b)

FIGURE 8: Variation of (a) $Q_{\text {intr }}$ (b) $K_{\text {La5 }}$ input variables under rain influent of Case 2.

respectively. Five main process variables including the total $S_{\mathrm{NH}}, \mathrm{N}_{\text {tot }}, \mathrm{BOD}_{5}, \mathrm{COD}$, and TSS are evaluated. The limit of effluent variables can be referred in Table 3. Overall in Case 1, in spite of total COD concentration, improvement on average effluents has been observed by ENon-PI compared to benchmark PI. Obvious enhancement on the $S_{\mathrm{NH}}$ resulted by ENon-PI with adaptive $k_{n}$ compared to benchmark PI under three input weathers. In particular, the improvement 

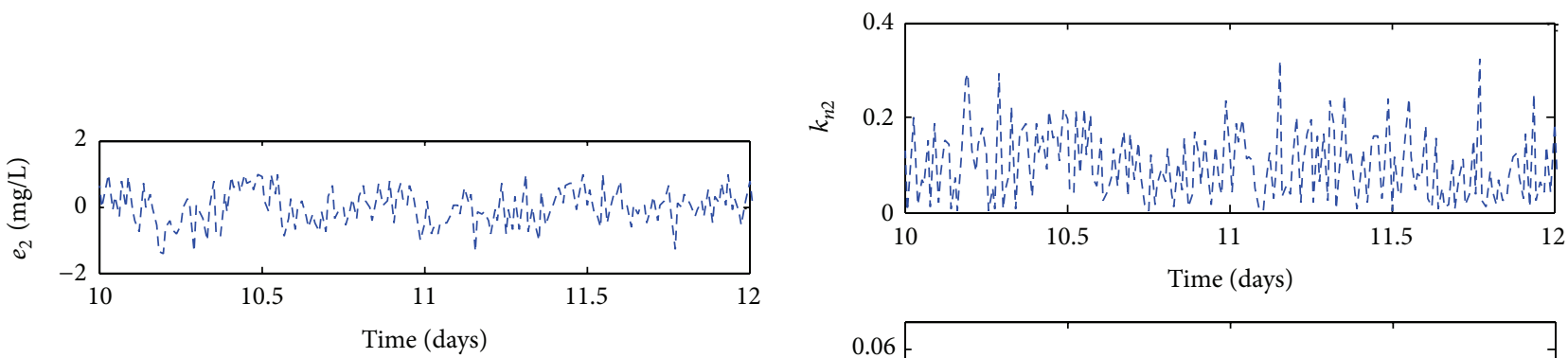

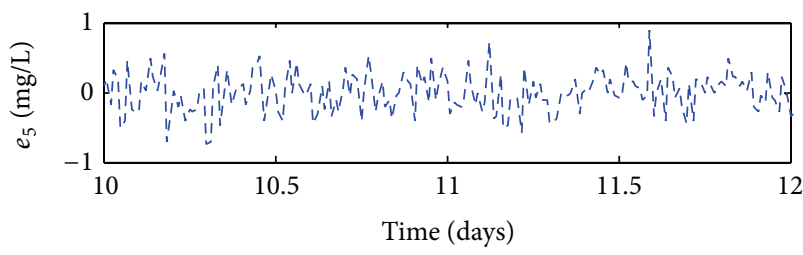

(a)

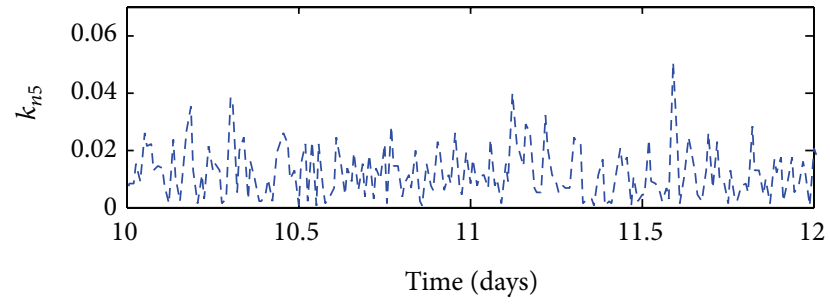

(b)

FIGURE 9: Variation of (a) error (b) rate variation under rain influent of Case 2.

TABLE 6: Average effluent concentrations for Case 1.

\begin{tabular}{|c|c|c|c|c|c|c|c|c|c|}
\hline & \multicolumn{3}{|c|}{ Dry } & \multicolumn{3}{|c|}{ Rain } & \multicolumn{3}{|c|}{ Storm } \\
\hline & $\begin{array}{c}\text { Benchmark } \\
\text { PI }\end{array}$ & $\begin{array}{c}\text { Fixed } \\
k_{n}\end{array}$ & $\begin{array}{c}\text { Adaptive } \\
k_{n}\end{array}$ & $\begin{array}{l}\text { Benchmark } \\
\text { PI }\end{array}$ & $\begin{array}{c}\text { Fixed } \\
k_{n}\end{array}$ & $\begin{array}{c}\text { Adaptive } \\
k_{n}\end{array}$ & $\begin{array}{c}\text { Benchmark } \\
\text { PI }\end{array}$ & $\begin{array}{c}\text { Fixed } \\
k_{n}\end{array}$ & $\begin{array}{c}\text { Adaptive } \\
k_{n}\end{array}$ \\
\hline $\begin{array}{l}S_{\mathrm{NH}} \text { conc } \\
/ \mathrm{mg} \mathrm{N} / \mathrm{L}\end{array}$ & 2.5392 & 2.3896 & 2.3881 & 3.226 & 3.2041 & 3.1954 & 3.0622 & 3.0395 & 3.041 \\
\hline $\begin{array}{l}\text { TSS conc } \\
/ \mathrm{mg} \mathrm{SS} / \mathrm{L}\end{array}$ & 13.0038 & 13.0038 & 13.0038 & 16.1768 & 16.175 & 16.1750 & 15.2737 & 15.2773 & 15.2724 \\
\hline $\begin{array}{l}\mathrm{N}_{\text {tot }} \text { conc } \\
/ \mathrm{mg} \mathrm{N} / \mathrm{L}\end{array}$ & 16.9245 & 16.8500 & 16.8505 & 16.9245 & 14.6539 & 14.6719 & 15.8676 & 15.7662 & 15.7666 \\
\hline $\begin{array}{l}\text { Total COD } \\
\text { conc/mg COD/L }\end{array}$ & 48.2201 & 48.2420 & 48.2427 & 45.4337 & 45.4314 & 45.4479 & 47.6626 & 47.6631 & 47.6639 \\
\hline $\mathrm{BOD}_{5}$ conc/mg/L & 2.7568 & 2.7615 & 2.7615 & 3.4557 & 3.4548 & 3.4557 & 3.2050 & 3.2049 & 3.2045 \\
\hline
\end{tabular}

TABLE 7: Average effluent concentrations for Case 2.

\begin{tabular}{|c|c|c|c|c|c|c|c|c|c|}
\hline & \multicolumn{3}{|c|}{ Dry } & \multicolumn{3}{|c|}{ Rain } & \multicolumn{3}{|c|}{ Storm } \\
\hline & $\begin{array}{c}\text { Benchmark } \\
\text { PI }\end{array}$ & $\begin{array}{c}\text { Fixed } \\
k_{n}\end{array}$ & $\begin{array}{c}\text { Adaptive } \\
k_{n}\end{array}$ & $\begin{array}{l}\text { Benchmark } \\
\text { PI }\end{array}$ & $\begin{array}{c}\text { Fixed } \\
k_{n}\end{array}$ & $\begin{array}{c}\text { Adaptive } \\
k_{n}\end{array}$ & $\begin{array}{l}\text { Benchmark } \\
\text { PI }\end{array}$ & $\begin{array}{c}\text { Fixed } \\
k_{n}\end{array}$ & $\begin{array}{c}\text { Adaptive } \\
k_{n}\end{array}$ \\
\hline $\begin{array}{l}S_{\mathrm{NH}} \text { conc } \\
/ \mathrm{mg} \mathrm{N} / \mathrm{L}\end{array}$ & 2.5392 & 2.5128 & 2.5126 & 3.226 & 3.2041 & 3.1954 & 3.0622 & 3.0395 & 3.0390 \\
\hline $\begin{array}{l}\text { TSS conc } \\
/ \mathrm{mg} \mathrm{SS} / \mathrm{L}\end{array}$ & 13.0038 & 13.0058 & 13.0058 & 16.1768 & 16.1798 & 16.1750 & 15.2737 & 15.2733 & 15.2734 \\
\hline $\begin{array}{l}\mathrm{N}_{\text {tot }} \text { conc } \\
/ \mathrm{mg} \mathrm{N} / \mathrm{L}\end{array}$ & 16.9245 & 16.8169 & 16.8160 & 16.9245 & 14.6539 & 14.6719 & 15.8676 & 15.7672 & 15.7666 \\
\hline $\begin{array}{l}\text { Total COD } \\
\text { conc/mg COD/L }\end{array}$ & 48.2201 & 48.2201 & 48.2201 & 45.4337 & 45.4314 & 45.4479 & 47.6626 & 47.6638 & 47.6639 \\
\hline $\mathrm{BOD}_{5}$ conc/mg/L & 2.7568 & 2.7560 & 2.7560 & 3.4557 & 3.4548 & 3.4549 & 3.2050 & 3.2049 & 3.2049 \\
\hline
\end{tabular}

of $S_{\mathrm{NH}}$ is maintained by ENon-PI with adaptive $k_{n}$ in Case 2. Besides, improvement on $\mathrm{N}_{\text {tot }}$ was recorded under dry and storm influents.

Next, the numbers of time that the effluent limits are not met during simulation obtained by ENon-PI for Case 1 are presented in Tables 8 and 9. The number of violation of $\mathrm{N}_{\text {tot }}$ is observed under dry weather while it is extended to TSS under the storm weather. It was proved that the numbers of the effluent increases above the effluent constraints are reduced from 7 to 6 compared to benchmark PI under dry weather. In the meantime, it reduces from 7 to 5 and 2 to 1 for $\mathrm{N}_{\text {tot }}$ and TSS under storm weather condition, respectively. To clarify, 

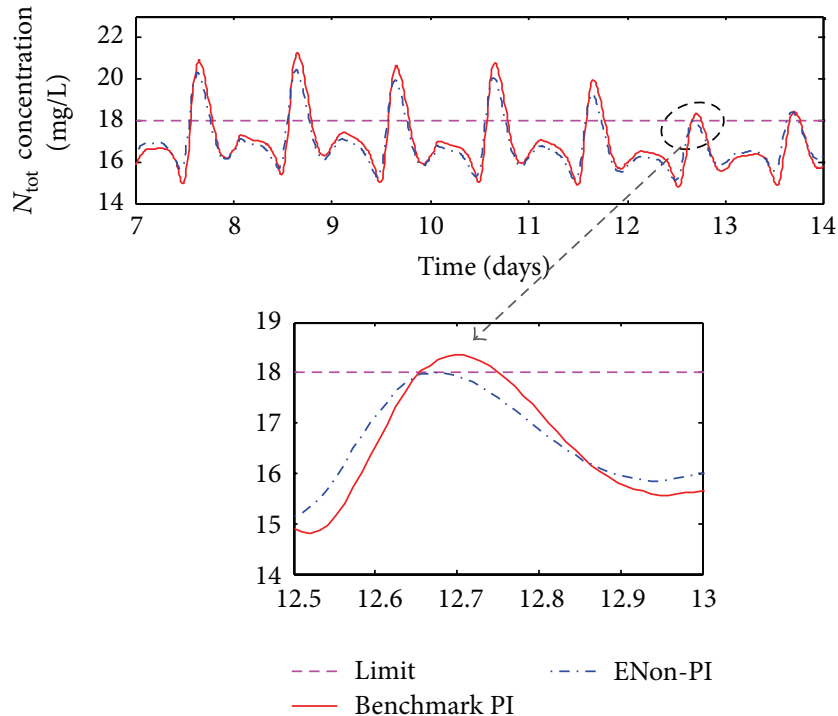

(a)

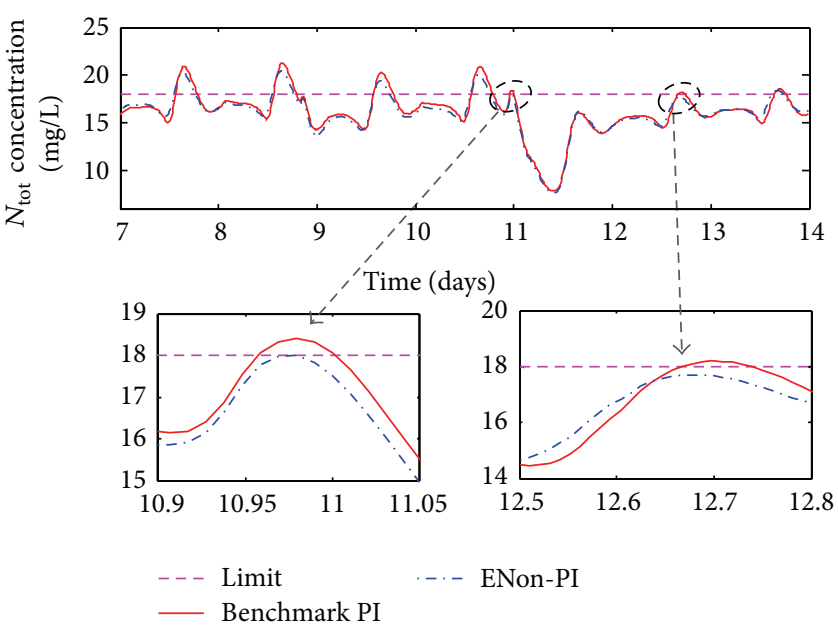

(b)

FIGURE 10: Effluent violations of $\mathrm{N}_{\text {tot }}$ for (a) dry (b) storm influents.

TABLE 8: Effluent violations under dry influent.

\begin{tabular}{cccc}
\hline & & Benchmark PI & ENon-PI \\
\hline \multirow{2}{*}{$\mathrm{N}_{\text {tot }}$} & Days & $\mathbf{1 . 2 8 1 3}$ & 1.1042 \\
& $\%$ & $\mathbf{1 8 . 3 0 3 6}$ & 15.7738 \\
& Occasion & $\mathbf{7 . 0 0 0 0}$ & 6.0000 \\
\hline
\end{tabular}

the $\mathrm{N}_{\text {tot }}$ effluent violation compared to benchmark PI under dry and storm influents is shown in Figure 10.

Next, the average AE consumed in the process of activated sludge is illustrated in Figure 11. As observed in Case 1, the $\mathrm{AE}$ is significantly reduced by ENon-PI with adaptive $k_{n}$ compared to benchmark PI under rain and storm events where the AE is minimized by 140.3118 and $46.7117 \mathrm{kwh}$ per day, respectively. Meanwhile, about $0.5474 \mathrm{kwh}$ per day
TABLE 9: Effluent violations under storm influent.

\begin{tabular}{cccc}
\hline & & Benchmark PI & ENon-PI \\
\hline \multirow{2}{*}{$\mathrm{N}_{\text {tot }}$} & Days & $\mathbf{1 . 0 9 3 8}$ & 0.9167 \\
& $\%$ & $\mathbf{1 5 . 6 2 5 0}$ & 13.0952 \\
& Occasion & $\mathbf{7 . 0 0 0 0}$ & 5.0000 \\
\hline \multirow{2}{*}{ TSS } & Days & $\mathbf{0 . 0 2 0 8}$ & 0.0104 \\
& $\%$ & $\mathbf{0 . 2 9 7 6}$ & 0.1488 \\
& Occasion & $\mathbf{2 . 0 0 0 0}$ & 1.0000 \\
\hline
\end{tabular}

of $\mathrm{AE}$ is saved with adaptive $k_{n}$ compared to fixed $k_{n}$ of ENon-PI controller under storm weather which is the lowest $\mathrm{AE}$ consumption in Case 2. In fact, even though slight improvements were recorded by Non-PI in Case 2 but the AE is mostly better than the benchmark PI controller. 


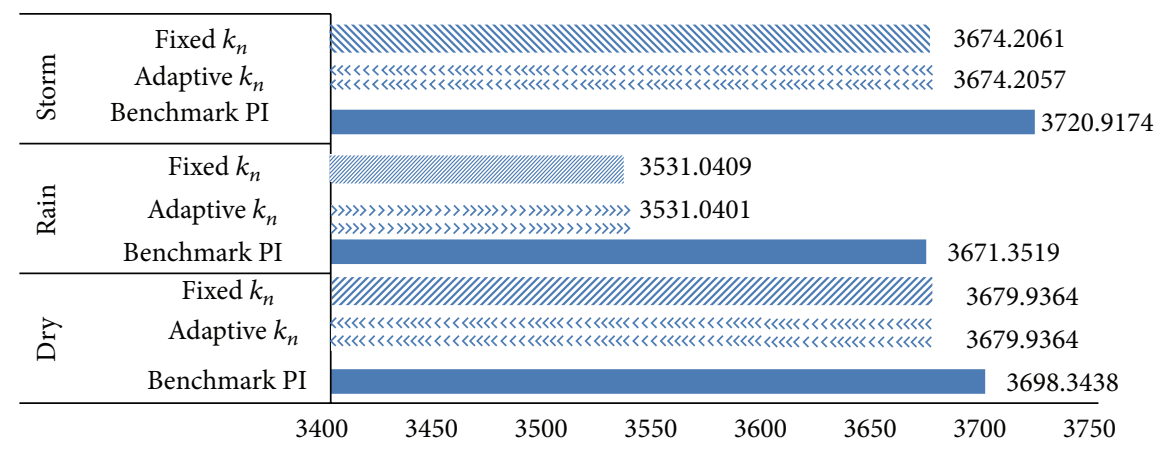

(a)

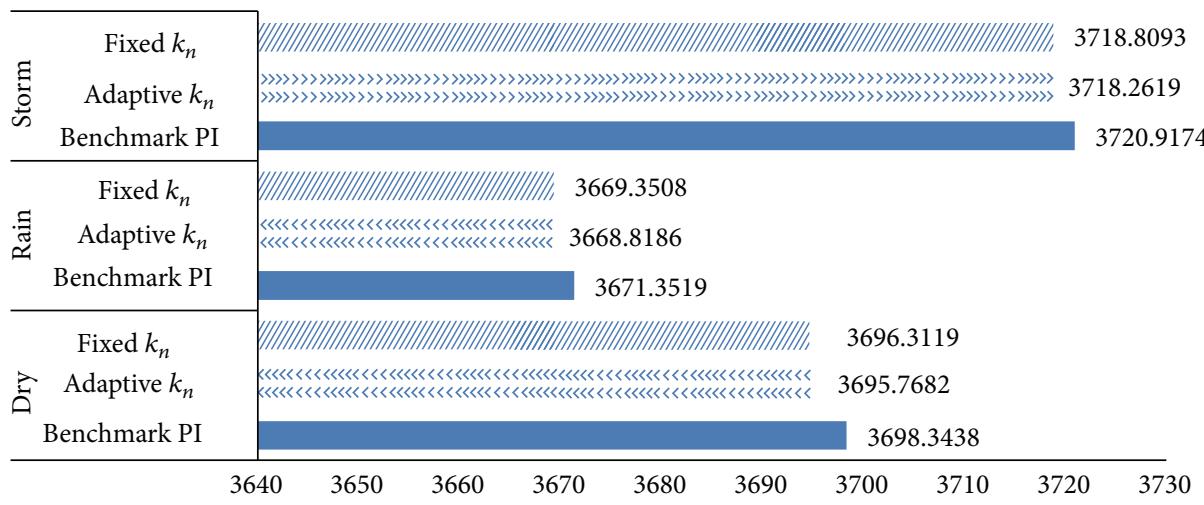

(b)

FIGURE 11: Comparative of aeration energy consumed (in kWh per day) for (a) Case 1 and (b) Case 2.

\section{Conclusion}

The aim of this paper is to design a simple but effective controller so that the performance of activated sludge process DO concentration control (Case 1) and the nitrogen removal (Case 2) of the WWTP are improved. For this work, the enhanced nonlinear PI (ENon-PI) controller is designed in which the conventional fixed-gain PI controller is incorporated with the bounded nonlinear function as to compensate the nonlinearity of the WWTP. The characteristic of the rate variation, $k_{n}$, is manipulated and automatically adapted based on adaptive interaction algorithm for a wide range of nonlinear gain.

From simulation, significant improvement is proved for $\mathrm{DO}_{345}$ control by ENon-PI compared to benchmark PI. Notice that the Case 1 deals with similar dynamic behaviors of DO concentrations, thus it easier to be controlled. In contrast, difficulties to control the simultaneous nitrate and $\mathrm{DO}_{5}$ concentrations for Case 2 are undeniable due to different natures of both control parameters. Even though slight improvements were recorded by Non-PI in Case 2 but it is mostly better than the benchmark PI controller.

The effectiveness to simplify the ENon-PI control structure with adaptive $k_{n}$ has been proved with significant improvement on both case studies. The performance comparison indicates that the proposed ENon-PI yields the most accurate strategy to control the DO concentration and the nitrogen removal process. For $\mathrm{DO}_{345}$ control, obvious improvement resulted where about 34.86\%, 31.4894\%, and $33.8202 \%$ of ISE are reduced compared to benchmark PI under dry, rain, and storm weathers, respectively. Again, more than $30 \%$ of ISE is reduced under three dynamic influent weathers, specifically for nitrate in nitrogen removal control. Meanwhile, more than $14 \%$ of IAE is reduced both simulation cases. Better average effluent concentrations and less number of the effluent violations resulted. Besides, lower average aeration energy is consumed specifically under rain and storm influents for $\mathrm{DO}_{345}$ control and in nitrate removal process, respectively. The proposed ENon-PI shows benefit for simple and practical implementation in controlling various dynamic natures of the activated sludge process.

\section{Conflict of Interests}

The authors declare that there is no conflict of interests regarding the publication of this paper.

\section{Acknowledgments}

The authors would like to thank the Ministry of Education (MOE), Universiti Teknikal Malaysia Melaka (UTeM), and Universiti Teknologi Malaysia (UTM). Their support is gratefully acknowledged. The authors wish to thank the IWA Task Group on the benchmark simulation plant. 


\section{References}

[1] R. Anders, Automatic control of an activated sludge process in a wastewater treatment plant-a Benchmark study [M.S. thesis], Department of Systems and Control, Information Technology, Uppsala University, 2000.

[2] A. Sanchez, Data-Driven Control Design of Wastewater Treatment Systems, Department of Electronic and Electrical Engineering, University of Strathclyde, Glasgow, Scotland, 2004.

[3] B. Holenda, E. Domokos, Á. Rédey, and J. Fazakas, "Dissolved oxygen control of the activated sludge wastewater treatment process using model predictive control," Computers and Chemical Engineering, vol. 32, no. 6, pp. 1270-1278, 2008.

[4] C. A. C. Belchior, R. A. M. Araújo, and J. A. C. Landeck, "Dissolved oxygen control of the activated sludge wastewater treatment process using stable adaptive fuzzy control," Computers and Chemical Engineering, vol. 37, pp. 152-162, 2012.

[5] V. Ramon, K. Reza, and N. A. Wahab, "N-removal on wastewater treatment plants: a process control approach," Journal of Water Resource and Protection, vol. 3, no. 1, pp. 1-11, 2011.

[6] S. Shoujun and L. Weiguo, "Application of improved PID controller in motor drive system," in PID Control, Implementation and Tuning, T. Mansour, Ed., InTech, 2011.

[7] A. Stare, D. Vrečko, N. Hvala, and S. Strmčnik, "Comparison of control strategies for nitrogen removal in an activated sludge process in terms of operating costs: a simulation study," Water Research, vol. 41, no. 9, pp. 2004-2014, 2007.

[8] M. Yong, P. Yongzhen, and U. Jeppsson, "Dynamic evaluation of integrated control strategies for enhanced nitrogen removal in activated sludge processes," Control Engineering Practice, vol. 14, no. 11, pp. 1269-1278, 2006.

[9] Y. X. Su, D. Sun, and B. Y. Duan, "Design of an enhanced nonlinear PID controller," Mechatronics, vol. 15, no. 8, pp. 10051024, 2005.

[10] R. D. Brandt and F. Lin, "Adaptive interaction and its application to neural networks," Information Sciences, vol. 121, no. 3-4, pp. 201-215, 1999.

[11] F. Lin, R. D. Brandt, and G. Saikalis, "Self-tuning of PID controllers by adaptive interaction," in Proceedings of the American Control Conference, pp. 3676-3681, June 2000.

[12] J. Alex, L. Benedetti, J. Copp et al., "Benchmark Simulation Model No. 1 (BSM1)," Tech. Rep., IWA Taskgroup on Benchmarking of Control Stategies for WWTPs, 2008.

[13] M. Henze, C. P. L. Grady Jr., W. Gujer, G. V. R. Marais, and T. Matsuo, Activated Sludge Model no. 1, 1987.

[14] I. Takács, G. G. Patry, and D. Nolasco, "A dynamic model of the clarification-thickening process," Water Research, vol. 25, no. 10, pp. 1263-1271, 1991.

[15] J. P. Segovia, D. Sbarbaro, and E. Ceballos, "An adaptive pattern based nonlinear PID controller," ISA Transactions, vol. 43, no. 2, pp. 271-281, 2004.

[16] H. Seraji, "A new class of nonlinear PID controllers with robotic applications," Journal of Robotic Systems, vol. 15, no. 3, pp. 161181, 1998.

[17] B. M. Badreddine, A. Zaremba, J. Sun, and F. Lin, Active damping of engine idle speed oscillation by applying adaptive PID control [Ph.D. thesis], The British Library, 2001.

[18] N. A. Wahab, R. Katebi, and J. Balderud, "Multivariable PID control design for activated sludge process with nitrification and denitrification," Biochemical Engineering Journal, vol. 45, no. 3 , pp. 239-248, 2009.
[19] J. B. Copp, COST Action 624: The COST Simulation Benchmark. Description and Simulation Manual, Office for Official Publications of the European Communities, 2002. 


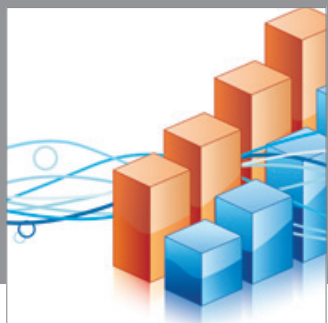

Advances in

Operations Research

mansans

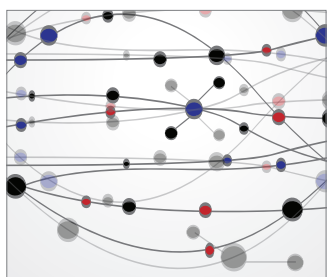

The Scientific World Journal
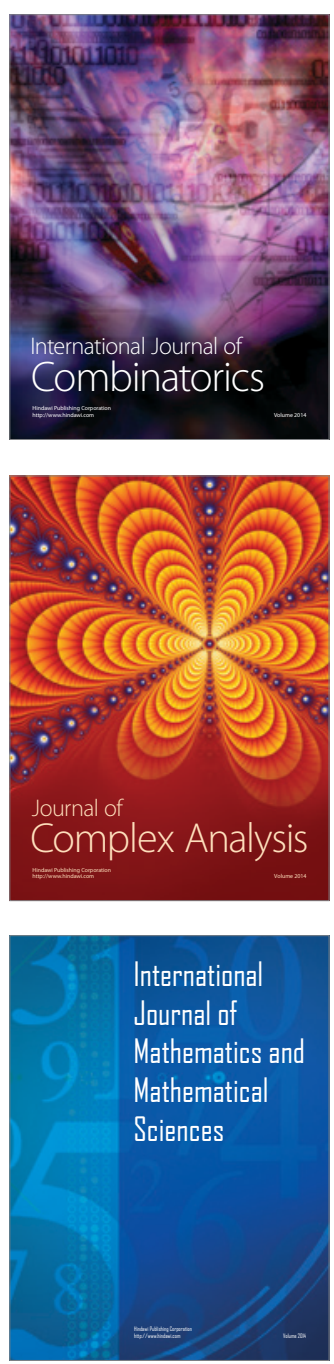
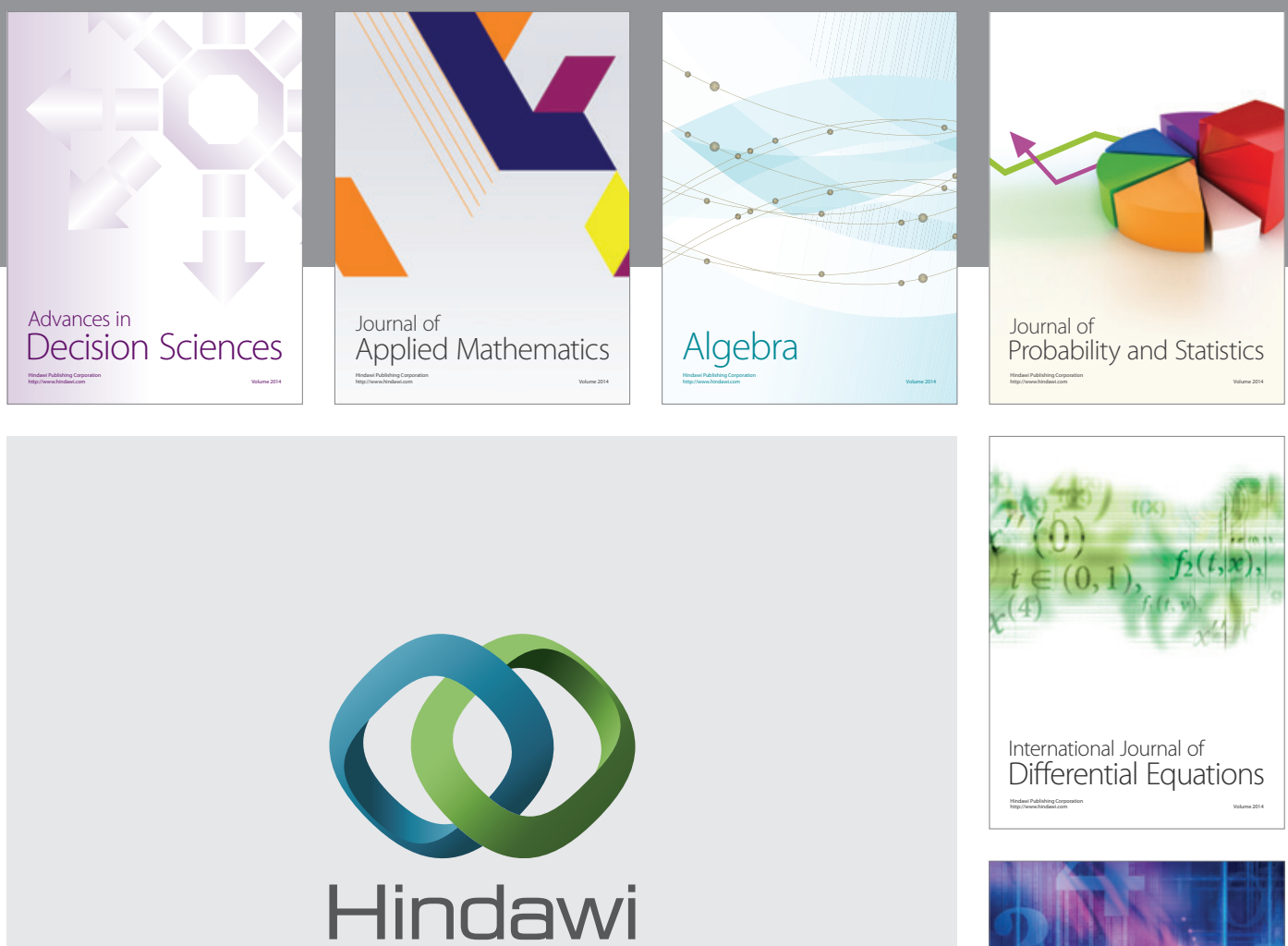

Submit your manuscripts at http://www.hindawi.com
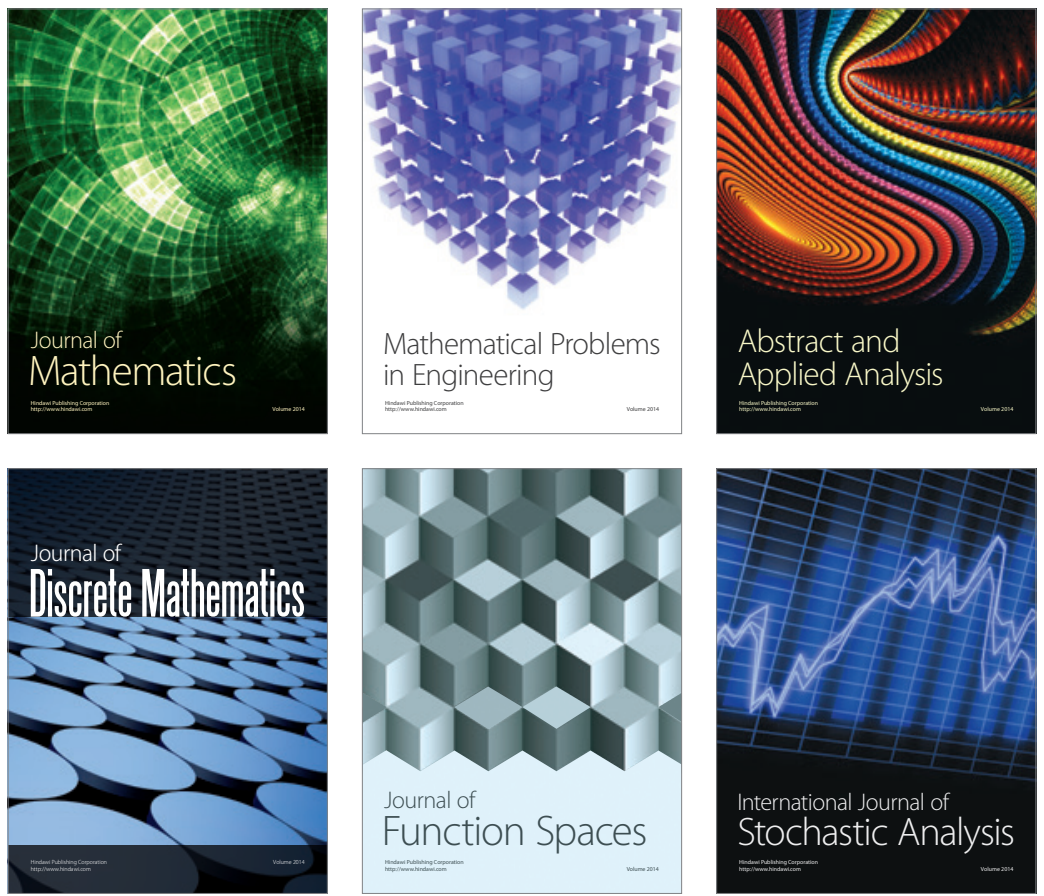

Journal of

Function Spaces

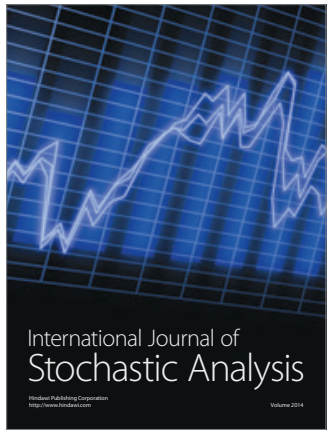

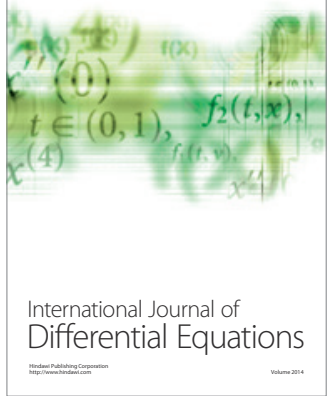
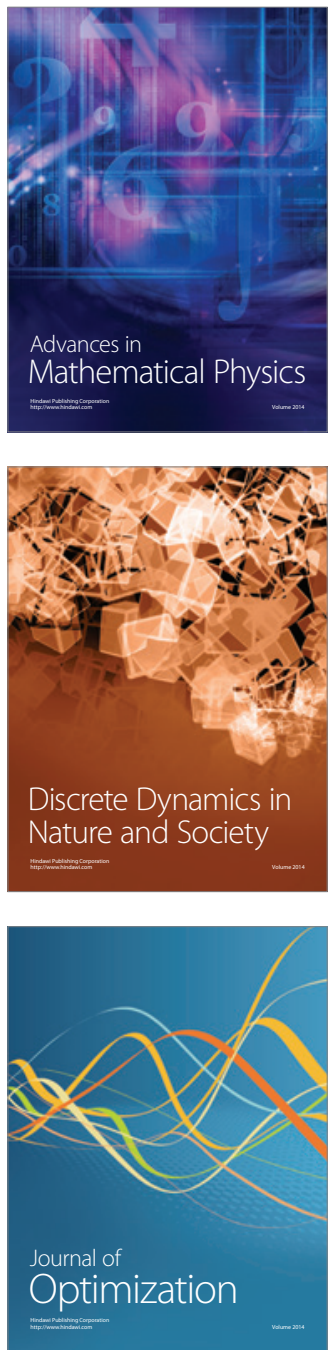